\title{
THE VALUE OF REMANIPULATING COLLES’ FRACTURES
}

\author{
MARGARET M. MCQUEEN, A. MACLAREN, JOHN CHALMERS
}

From the Royal Infirmary, Edinburgh

The value of remanipulating a Colles' fracture which has redisplaced after primary reduction was assessed in 50 patients. In those over 60 years old, remanipulation failed to achieve a lasting improvement in position, while the majority of those under 60 years maintained a significant improvement in dorsal angulation. It is concluded that the elderly patient does not benefit from this procedure.

Despite many reports published since Colles described the fracture which bears his name, considerable controversy about its management persists. Although it is standard practice in many centres to re-reduce Colles' fractures which have displaced after initial reduction, little is known about the value of this in relation to the final position of the fracture. In this report we aim to assess this procedure.

\section{PATIENTS AND METHODS}

A retrospective review was undertaken of 50 patients who had been treated for a Colles' fracture and were subsequently admitted to the Orthopaedic Unit of the Royal Infirmary of Edinburgh for remanipulation. All the patients had had reduction of their original fracture within 48 hours of injury, and immobilisation by a plaster of Paris backslab. Between one and two weeks after the initial reduction a remanipulation was undertaken because of secondary displacement.

There were 44 women and six men with a mean age of 59.7 years (range 21 to 86 years); 28 patients were 60 years of age or over and 22 patients were less than 60 years of age.

Dorsal angulation and radial shift (Van der Linden and Ericson 1981) were measured on anteroposterior and lateral radiographs after the initial reduction, immediately before and after remanipulation and on final radiographs taken at least six weeks from the time of injury (Figs 1 and 2). These measurements were then related to the age of the patient.

Statistical analysis was performed using the paired Student's $t$-test.

M. M. McQueen, FRCS, Lecturer

J. Chalmers. MD. FRCS, Consultant Orthopaedic Surgeon

Princess Margaret Rose Orthopaedic Hospital. Fairmilehead, Edinburgh EHIO 7ED. Scotland.

A. MacLaren, M B ChB. Orthopaedic Registrar

Glan Clwyd Hospital, Rhyl. North Wales.

Requests for reprints should be sent to Miss M. M. McQueen.

( 1986 British Editorial Society of Bone and Joint Surgery $0301-620 \times 86 / 2016 \$ 2.00$

\section{RESULTS}

Dorsal angulation. In all patients the position after initial reduction and immediately after remanipulation was satisfactory with less than 10 of dorsal angulation.

In the 28 patients more than 60 years old the mean dorsal angle before remanipulation was 22.9 and on the final radiograph it was 22.2 , a difference which was not statistically significant. Ten of these patients had a mean improvement in dorsal angulation of 9.4 ; three patients

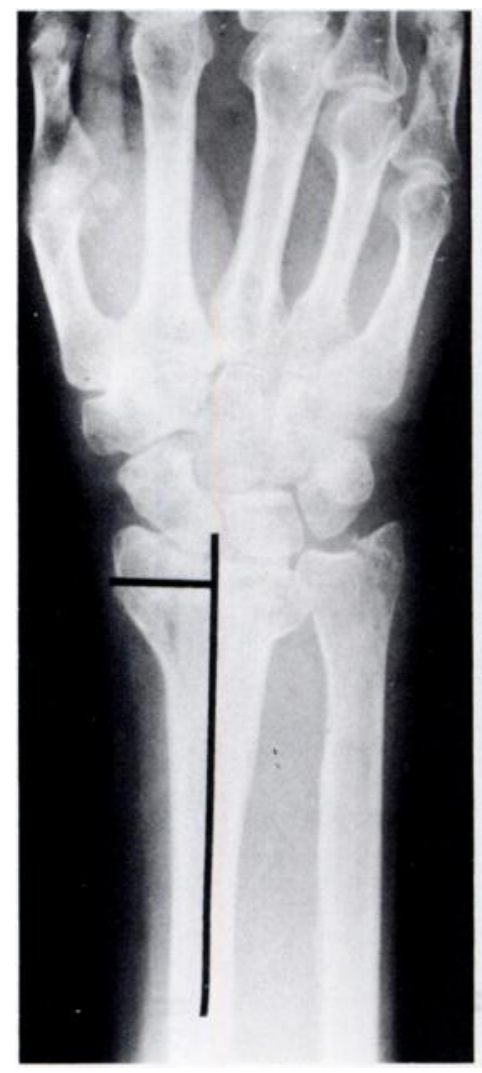

Fig. 1

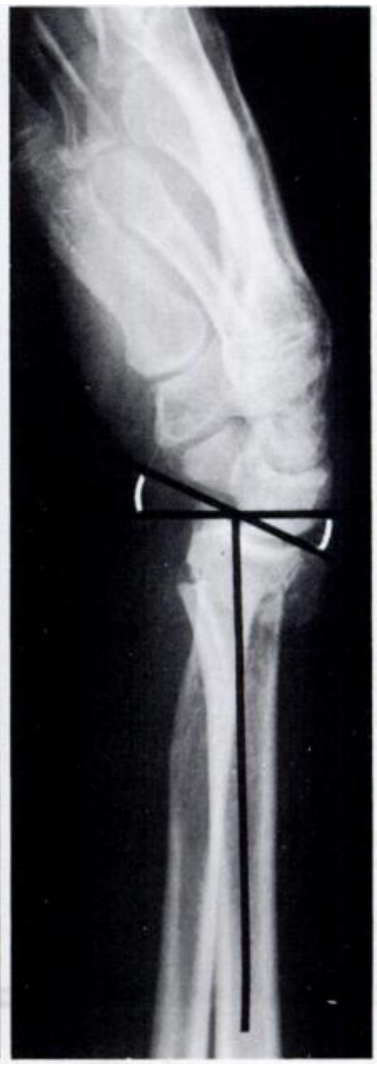

Fig. 2
Figure 1--Radial shift is measured on an anteroposterior radiograph as the maximum distance between a line projecting from the midline of the shaft of the radius and the lateral cortex of its lower end. Figure 2 The dorsal angle is that between a line at 90 to the long axis of the radius and a line joining the most anterior and most posterior points of the radial joint surface. 
Table I. Mean values of dorsal angulation in degrees for 50 patients having remanipulation of a Colles" fracture

$\begin{array}{llll}\text { Group } & \begin{array}{l}\text { Number } \\ \text { of patients }\end{array} & \begin{array}{l}\text { Before } \\ \text { remanipulation }\end{array} & \begin{array}{l}\text { Final } \\ \text { position }\end{array} \\ \text { 60) years and older } & & 22.9 & 22.2^{*} \\ \text { All cases } & 28 & 24.7 & 15.3 \\ \text { Improvement } & 10 & 15.6 & 15.6 \\ \text { No change } & 3 & 23.2 & 28.2 \\ \text { Deterioration } & 15 & \end{array}$

Linder 60 years

$\begin{array}{lrrr}\text { All cases } & 22 & 18.6 & 9.8 \\ \text { Improvement } & 16 & 19.8 & 6.1 \\ \text { No change } & 3 & 16.6 & 16.6 \\ \text { Deterioration } & 3 & 14.0 & 22.3\end{array}$

${ }^{*}$ Differences between angle before remanipulation and at final assessment were not significant in the older group and highly significant in the younger group $(P<0.005)$

showed no change but 15 showed a mean deterioration of 5 on the final radiograph (Table I).

In the remaining patients, those under 60 years of age, the mean dorsal angle before remanipulation was 18.6 ; on the final radiographs this was 9.8 . This difference was statistically significant $(P<0.005)$. Of these 22 patients 16 had a mean improvement in dorsal angulation of 13.7 ; three showed no change and three deteriorated by a mean of 8.3 (Table I).

Radial shift. In the older group 16 of the 28 patients showed no change in the radial shift after remanipulation. Six showed improvement and seven deteriorated but in no patient was the difference in radial shift more than $3 \mathrm{~mm}$. In the younger group 12 of the 22 patients showed no change in the radial shift after remanipulation. five showed improvement and five deteriorated; here, too, there was no difference greater than $3 \mathrm{~mm}$.

\section{DISCUSSION}

It is generally agreed that if a Colles' fracture has displaced by the time of radiographic follow-up one to two weeks after initial reduction, it should be remanipulated. However, there have been few reports on the value of this in relation to the final position of the fracture. In Lidström's series (1959) 20 fractures were remanipulated but the position was improved in only 11 cases. Collert and Isacson (1978) found that only two of 15 patients whose fractures had early re-reduction (within one week of primary reduction), and 15 of 30 who had late re-reduction (in the second week after primary reduction), showed lasting improvement. These results agree with our findings, in which 26 of 50 patients had lasting improvement after late re-reduction. However, it is clearly seen that the younger the patient, the better the chance of a lasting improvement after remanipulation.

The relationship between radiological results and final function is central to the assessment of the value of remanipulating Colles` fractures. Lidström (1959) found that dorsal angulation did not affect function provided that it did not exceed 10 ; he concluded, however, that a satisfactory reduction was no guarantee of satisfactory functional results. Nonetheless, Bacorn and Kurtzke (1953) demonstrated a direct relationship between residual deformity and mean disability, and this has been confirmed more recently by Sarmiento et al. (1975), Green (1975) and Cooney, Linscheid and Dobyns (1979). It is therefore reasonable to strive for a result which is as near to normal anatomy as possible.

Compression of the dorsal cortex contributes to the instability of a Colles fracture and the differing results in the two age groups could be explained on this basis. In younger patients the quality of callus formed on the dorsal cortex is likely to be better and might explain why such patients maintain the re-reduced position.

If an anatomical result is desired in an elderly patient after a Colles' fracture, other methods of reduction and fixation can be considered; but if radiological perfection is not considered essential then these elderly patients should be excused such procedures.

\section{REFERENCES}

Bacorn RW, Kurtzke JF. Colles fracture: a study of two thousand cases from the New York State Workmen`s Compensation Board. J Bone Joint Surg $[\mathrm{Am}]$ 1953:35 A:643 58.

Collert S, Isacson J. Management of redislocated Colles' fractures. C'lin Orthop 1978:135: 183-6.

Cooney WP III, Linscheid RL, Dobyns JH. External pin fixation for unstable Colles' fractures. J Bone Joint Surg $[\mathrm{Am}]$ 1979:61 A: 8405.

Green DP. Pins and plaster treatment of comminuted fractures of the distal end of the radius. $J$ Bone Joint Surg $[A m]$ 1975:57 A 30410.

Lidström A. Fractures of the distal end of the radius: a clinical and statistical study of end results. Acta Orthop Scand 1959:Suppl 41.

Sarmiento A, Pratt GW, Berry NC, Sinclair WE. Colles' fractures: functional bracing in supination. J Bome Joint Surg [.4m] 1975: 57 A: 3117 .

Van der Linden W, Ericson R. Colles fracture: how should its displacement be measured and how should it be immobilized"? J Bone Joint Surg $[A m] 1981: 63-\mathbf{A}: 1285-8$. 